\title{
Maxadilan-simile expression in Nyssomyia neivai, a sandfly vector in an endemic region of Brazil, and its immunogenicity in patients with American tegumentary leishmaniasis
}

\author{
Juliana Aires ${ }^{1}$, Claudio Casanova ${ }^{2}$, Sebastian Vernal' ${ }^{1}$, Margarida Nascimento ${ }^{3}$, \\ Sandra Rodrigues ${ }^{4}$, Ethan A Lerner ${ }^{5}$, Ana Maria Roselino ${ }^{1,4} /+$
}

\author{
${ }^{1}$ Universidade de São Paulo, Faculdade de Medicina de Ribeirão Preto, Departamento de Clínica Médica, Divisão de Dermatologia, \\ Ribeirão Preto, SP, Brasil \\ ${ }^{2}$ Secretaria de Estado da Saúde, Superintendência de Controle de Endemias, Mogi Guaçu, SP, Brasil \\ ${ }^{3}$ Universidade de São Paulo, Faculdade de Medicina de Ribeirão Preto, Laboratório de Sorologia, Hospital das Clínicas, Ribeirão Preto, SP, Brasil \\ ${ }^{4}$ Universidade de São Paulo, Faculdade de Medicina de Ribeirão Preto, Departamento de Clínica Médica, Laboratório de Biologia \\ Molecular, Ribeirão Preto, SP, Brasil \\ ${ }^{5}$ Cutaneous Biology Research Center, Massachusetts General Hospital, Harvard Medical School, Boston, MA, USA
}

BACKGROUND Maxadilan (Max) is a salivary component in the sandfly Lutzomyia longipalpis (Lutz \& Neiva 1912), a vector of visceral leishmaniasis. Max has a powerful vasodilatory effect and is a candidate vaccine that has been tested in experimental leishmaniasis. Nyssomyia neivai (Pinto 1926) is a vector of the pathogen responsible for American tegumentary leishmaniasis (ATL) in Brazil.

OBJECTIVE We searched for Max expression in Ny. neivai and for antibodies against Max in ATL patients.

METHODS cDNA and protein were extracted from the cephalic segment, including salivary glands, of $N y$. neivai and analysed by polymerase chain reaction, DNA sequencing, and blotting assays. The results were compared with data obtained from $L u$. longipalpis samples. We quantified antibodies against Max in serum samples from 41 patients with ATL (31 and 10 with the cutaneous and mucocutaneous forms, respectively) and 63 controls from the endemic northeastern region of São Paulo state, using enzyme-linked immunosorbent assay.

FINDINGS Recognition of a Max-simile peptide by specific antibodies confirmed expression of a Max sequence in $N y$. neivai (GenBank EF601123.1). Compared to controls, patients with ATL presented higher levels of antibodies against Max ( $\mathrm{p}=0.004)$; $24.4 \%$ of the patients with ATL and 3.2\% of the controls presented anti-Max levels above the cutoff index $(p=0.014)$. The antiMax levels were not associated with the specific clinical form of ATL, leishmanin skin test response, absence or presence of amastigotes in histopathologic exam, results of indirect immunofluorescence testing for leishmaniasis, or duration of cutaneous form disease.

MAIN CONCLUSION High serum anti-Max levels did not protect patients against ATL, but confirmed previous natural exposure to $N y$. neivai bites in this ATL endemic region.

Key words: Maxadilan protein - leishmaniasis - Psychodidae

Leishmaniasis encompasses a spectrum of diseases caused by an obligate intramacrophage protozoan belonging to the genus Leishmania (Kinetoplastida: Trypanosomatidae). The parasite is transmitted by the bite of phlebotomine vectors (Diptera: Psychodidae: Phlebotominae) that inoculate promastigote forms of Leishmania, along with saliva, into the host's skin while acquiring a blood meal (Roberts 2005). Pharmacological activities in the sandfly saliva promote blood feeding and cell functions, as well as modulate the host's immune response (Champagne 1994).

doi: 10.1590/0074-02760160351

Financial support: FAEPA, University Hospital, Ribeirão Preto Medical

School, University of São Paulo, Brazil.

SV received a scholarship from CAPES.

+ Corresponding author: amfrosel@fmrp.usp.br

Received 3 August 2016

Accepted 31 October 2016
Maxadilan (Max) is a 7-kDa peptide present in the salivary glands of the sandfly Lutzomyia longipalpis (Lutz $\&$ Neiva 1912). This species has been implicated in the transmission of Leishmania (Leishmania) infantum chagasi (Cunha \& Chagas 1937), the main causative agent of visceral leishmaniasis (VL) in Brazil (Lainson \& Rangel 2005). Max was the first molecule to be identified in sandfly saliva (Lerner et al. 1991), and it is a powerful vasodilator. Max inoculated into experimental animals exacerbates Leishmania infection, similar to inoculation of whole salivary glands (Morris et al. 2001). This peptide can redirect a Th1 response to Th2, up-regulating IL-10 and TGF- $\beta$ production and suppressing IL-12p 40 , TNF- $\alpha$, and NO production (Titus et al. 2006, Brodie et al. 2007).

The Max homologue in Nyssomyia intermedia (Lutz $\&$ Neiva 1912) $(=$ Lu. intermedia), a vector of the pathogen responsible for American tegumentary leishmaniasis (ATL) in Brazil, is highly divergent - its shows only $34 \%$ sequence identity with Max from $\mathrm{Lu}$. longipalpis and is less abundant (de Moura et al. 2013). The functional transcriptome of $\mathrm{Lu}$. ayacuchensis (Cáceres \& 
Galati 1988), a vector of cutaneous leishmaniasis (Kato et al. 2013), did not indicate the presence of Max in salivary glands. Hence, the amount of Max in the salivary gland of a vector may affect the outcome of Leishmania infection (Warburg et al. 1994).

Autochthonous cases of ATL have been reported in the northeastern region of the state of São Paulo. Leishmania (Viannia) braziliensis (Viana 1911) and Leishmania (Leishmania) amazonensis (Lainson \& Shaw 1972) are the species associated with the cutaneous and mucocutaneous forms of ATL (Cruz et al. 2013, NeitzkeAbreu et al. 2014). However, to our knowledge, autochthonous cases of VL have not yet been reported in this region (Casanova et al. 2015).

The sandflies Ny. intermedia and Ny. neivai (Pinto 1926) (= syn. Lu. intermedia) are the main vectors of Leishmania (V.) braziliensis in the state of São Paulo. However, only $N y$. neivai has been identified in systematic collections in the municipalities of that region (Andrade Filho et al. 2007). Lu. longipalpis is mainly found in the western region of the state of São Paulo, but it has not been associated with leishmaniasis in the northeastern region of this state (Casanova et al. 2015).

Our objective was to verify the presence of antibodies against Max in patients with ATL, because it has been studied mainly in animal models and only rarely in humans. First, in this study we demonstrated Max-simile gene and protein expression in Ny. neivai. Then, we compared anti-Max IgG antibody levels in autochthonous cases of ATL to those in healthy controls, which confirmed exposure to bites of the $N y$. neivai vector in the northeastern region of São Paulo state, Brazil.

\section{MATERIALS AND METHODS}

Maxadilan - The recombinant peptide was produced in Escherichia coli as described previously (Lerner \& Shoemaker 1992).

Rabbit immunisation against Max peptide - Briefly, $100 \mu \mathrm{L}$ of Max $(150 \mu \mathrm{g} / \mathrm{mL})$ was diluted in phosphate buffered saline (PBS) to a final volume of 2,000 $\mu \mathrm{L}$ and distributed into $500-\mu \mathrm{L}$ aliquots. On the first day, 500 $\mu \mathrm{L}$ of complete Freund's adjuvant (Sigma-Aldrich, Saint Louis, MO, USA) was mixed with an aliquot of Max, and a rabbit was injected with the mixture in each hip. Nine days later, another dose was injected in the foreleg and shoulder of the rabbit. On day 20, a third dose was injected at four points subcutaneously. Rabbit serum was tested by counterimmunoelectrophoresis on a $1 \%$ agarose gel before and after immunisation (positive pole) against Max (negative pole). Runs were performed using sodium barbital buffer in an electric current of $30 \mathrm{~mA}$ for $60 \mathrm{~min}$, and then agarose gel was stained with Coomassie Blue (Sigma-Aldrich, Saint Louis, MO, USA).

Sandflies and RNA-DNA-protein extraction - Laboratory-colonised $\mathrm{Lu}$. longipalpis were provided by Alda Hawk, PhD, Fiocruz-Belo Horizonte, state of Minas Gerais, Brazil; Ny. neivai specimens were wild caught and identified by Claudio Casanova, SUCENMogi Guaçu, state of São Paulo, Brazil. The cephalic segments, including the salivary glands, of $L u$. longi- palpis and Ny. neivai specimens were used for extraction by the Trizol method. In this report, the sandfly species names are presented in accordance with Galati's classification system (Galati 2003) and, when cited for the first time, are followed by the corresponding nomenclature of Young and Duncan in brackets (Young $\&$ Duncan 1994). Abbreviations of generic names follow the proposal of Marcondes (2007).

Protein electrophoresis - Max $(0.33 \mu \mathrm{g} / \mathrm{mL})$ and proteins extracted from $\mathrm{Lu}$. longipalpis $(0.02 \mu \mathrm{g} / \mathrm{uL})$ and from $N y$. neivai $(0.01 \mu \mathrm{g} / \mathrm{mL})$ were run in a $12.5 \%$ acrylamide gel using a Mini Protean II (Bio-Rad, Hercules, CA, USA); the acrylamide gel was stained by the silver method.

Immunoblotting - Max and protein extracts submitted to electrophoresis were transferred to a $0.2-\mu \mathrm{m}$ nitrocellulose membrane (Bio-Rad, Hercules, CA, USA) (Mini Trans-Blot Cell, Bio-Rad, Hercules, CA, USA). Then, each strip was incubated with a serum sample (1:20) for $2 \mathrm{~h}$. After washing with thiosulphate-citrate-bile salts-sucrose (TCBS), a protein G-horseradish peroxidase (HRP) conjugate was incubated with the strips for $2 \mathrm{~h}$, which was followed by colour revelation with an HRP-conjugated substrate (Bio-Rad, Hercules, CA, USA).

Comparison of the Ny. neivai - Max DNA sequence with that of Lu. longipalpis using polymerase chain reaction-restriction fragment length polymorphism (PCR-RFLP). The Max DNA fragment was amplified with specific primers (Invitrogen, Carlsbad, CA, USA): sense-GCCATAGATGACTGCCAGAAGC and antisense-TTCCAGGTAGTTGGGAGGTATCC. PCR was performed in a thermocycler (Thermo Fisher, Waltham, MA, USA) with a final volume of $25 \mu \mathrm{L}: 2.5 \mu \mathrm{L}$ of $10 \times$ buffer, $5 \mu \mathrm{L}$ of $2 \mathrm{mM}$ dNTP, $10.3 \mu \mathrm{L}$ of distilled water, 1 $\mu \mathrm{L} 100$ pmol of each primer, and $20 \mu \mathrm{L}$ of Taq polymerase. A total of 35 cycles were run as follows: one cycle at $93^{\circ} \mathrm{C}$ for $30 \mathrm{sec}$, one cycle at $94^{\circ} \mathrm{C}$ for $3 \mathrm{~min}$ and $30 \mathrm{sec}$, one cycle at $52^{\circ} \mathrm{C}$ for $1 \mathrm{~min}$, one cycle at $72^{\circ} \mathrm{C}$ for $1 \mathrm{~min}$, and a final cycle at $72^{\circ} \mathrm{C}$ for $10 \mathrm{~min}$. Amplification of a 106 -bp product was confirmed in a $10 \%$ acrylamide gel. $H h a \mathrm{I}$ and $R s a \mathrm{I}$ enzyme restriction was performed. HhaI acts at the $\mathrm{GCG}^{\wedge} \mathrm{C}$ restriction site, generating 30-bp and 80 -bp sequences. $R s a \mathrm{I}$ acts in $\mathrm{GT}^{\wedge} \mathrm{AC}$, resulting in two 50-bp sequences.

Reverse transcription-PCR (RT-PCR) - RNA $(12 \mu \mathrm{L})$ extracted from both sandflies species was added to 0.7 $\mu \mathrm{L}$ of RNase inhibitor, $4 \mu \mathrm{L}$ of $5 \times$ RT buffer, $1 \mu \mathrm{L}$ of $10 \mu \mathrm{M}$ dNTP, $0.6 \mu \mathrm{L}$ of RT (Invitrogen, Carlsbad, CA, USA), and $1.7 \mu \mathrm{L}$ of distilled water at $42^{\circ} \mathrm{C}$ for $90 \mathrm{~min}$, followed by storage at $-20^{\circ} \mathrm{C}$. cDNA was used in the PCR assay described above.

Sequencing of PCR products - PCR was performed with the sense primer-CGTGTTTGCCTTCAGTAAGTTCT to amplify a long fragment and for sequencing. A 246-bp fragment was sequenced following the manufacturer's recommendations (DNA Sequencing Kit Big Dye Terminator, Applied Biosystem, Foster City, CA, USA; and ABI Prism 310 Genetic Analyzer, Applied Biosystem, Foster City, CA, USA). 
Study population - Patients were identified at the University Hospital, Ribeirão Preto Medical School, University of São Paulo, Brazil, which is the main reference institution for diagnosis and treatment of ATL in the northeastern region of the state of São Paulo. A diagnosis of ATL was confirmed with at least two of the following criteria: clinical-epidemiological diagnosis compatible with ATL; positive leishmanin skin test (LST; Adolfo Lutz, Brazil) defined as induration $\geq 5 \mathrm{~mm} 48$ $72 \mathrm{~h}$ after injection; histopathology of a skin or mucosa sample indicative of ATL, with or without visualisation of the amastigote form; indirect immunofluorescence (IIF) test (Fiocruz, Brazil); and PCR result positive for the L. Viannia subgenus (Vernal et al. 2016). All patients were negative for anti-HIV antibodies.

Patients' serum samples were selected randomly from a serum bank at the Laboratory of Dermatology, University Hospital. The control group consisted of 63 healthy donors selected randomly at the Ribeirão Preto Blood Center.

In-house enzyme-linked immunosorbent assay (ELISA) standardised with Max peptide - Briefly, Max diluted in carbonate-bicarbonate buffer $(125 \mu \mathrm{g} / \mathrm{mL})$ was used to coat a microplate (Immulon, Thermofisher, Waltham, MA, USA) at $4^{\circ} \mathrm{C}$ for $48 \mathrm{~h}$. After washing with PBS-
Tween 20 (T20), $50 \mu \mathrm{L}$ of each serum sample diluted in PBS-TM is Phosphate-buffered saline (PBS) plus Tween 20 plus Milk, plus $5 \%$ fat free milk (1:50) was incubated at $37^{\circ} \mathrm{C}$ for $2 \mathrm{~h}$. After washing, peroxidase-conjugated anti-human IgG (Sigma-Aldrich, Saint Louis, MO, USA) was incubated with plates at $37^{\circ} \mathrm{C}$ for $2 \mathrm{~h}$, and $100 \mu \mathrm{L}$ of chromogenic substrate (o-phenylenediamine dihydrochloride, Sigma-Aldrich, Saint Louis, MO, USA) was incubated with plates at room temperature in the dark for 15 min, followed by the addition of $50 \mu \mathrm{L}$ of stop solution ( $1 \mathrm{~N}$ $\mathrm{H}_{2} \mathrm{SO}_{4}$ ). Colour development was observed in an ELISA reader (Labsystem Multiskan MS, Artisan, Champaign, IL, USA) at $492 \mathrm{~nm}$. Anti-Max values were expressed as index values: the optical density (OD) of each sample was divided by the cutoff (the mean anti-Max OD values in the control group plus two standard deviations).

Statistical analysis - Patients' data are summarised the table. The Student's $t$-test was used to compare the results of two groups. Categorical variables were compared by Chi-square $\left(\chi^{2}\right)$ test. Fisher's exact test was used when data were sparse. Significance was set at $p<0.05$; a twotailed comparison was employed. The statistical analyses were performed using GraphPad Prism 6 software.

Ethics - This study was approved by the Human Ethics Committee (\#5.886/2002) of the University Hospital

TABLE

Demographic and laboratory data from patients with cutaneous and mucocutaneous clinical forms of American tegumentary leishmaniasis

\begin{tabular}{|c|c|c|c|}
\hline & Cutaneous form & Mucocutaneous form & $\mathrm{p}$-value \\
\hline & Median (min/max) & Median (min/max) & \\
\hline Age (years) & $44.0(3.0 / 64.0)$ & $51.5(22.0 / 65.0)$ & 0.560 \\
\hline \multirow[t]{2}{*}{ Duration of disease (months) } & $4.0(1.0 / 31.0)$ & $66.0(4.0 / 300.0)$ & $<0.001$ \\
\hline & N (\%) & $\mathrm{N}(\%)$ & \\
\hline \multicolumn{4}{|l|}{ Gender } \\
\hline Male & $23(74.2)$ & $10(100.0)$ & \multirow{2}{*}{0.083} \\
\hline Female & $8(25.8)$ & $0(0)$ & \\
\hline \multicolumn{4}{|l|}{ Leishmanin skin test } \\
\hline Positive & $18(64.3)$ & $7(77.8)$ & \multirow{2}{*}{0.376} \\
\hline Negative & $10(35.7)$ & $2(22.2)$ & \\
\hline \multicolumn{4}{|l|}{ Presence of amastigotes ${ }^{\mathrm{a}}$} \\
\hline Present & $9(29.0)$ & $4(40.0)$ & \multirow{2}{*}{0.390} \\
\hline Absent & $22(71.0)$ & $6(60.0)$ & \\
\hline \multicolumn{4}{|l|}{ IIF } \\
\hline Reactive & $18(58.1)$ & $6(60.0)$ & \multirow{2}{*}{0.606} \\
\hline Non-reactive & $13(41.9)$ & $4(40.0)$ & \\
\hline \multicolumn{4}{|l|}{ PCR } \\
\hline Positive & $18(58.0)$ & $4(40.0)$ & \multirow{3}{*}{1.00} \\
\hline Negative & $10(32.3)$ & $3(30.0)$ & \\
\hline Not done & $3(9.7)$ & $3(30.0)$ & \\
\hline
\end{tabular}

$a$ : on histopathological biopsy sample; IIF: indirect immunofluorescence; min: minimum; max: maximum; N: number of patients. 
of the Ribeirão Preto Medical School, University of São Paulo, Brazil, in accordance with the ethical standards of the Helsinki Declaration (1964, amended most recently in 2008) of the World Medical Association. All patients included in the study signed to indicate their informed consent prior to participation.

\section{RESULTS}

Immunoblotting indicated Max-simile peptide in the $N y$. neivai protein extract - Similar molecular weight fractions, including a 7-kDa peptide, were present in both the Ny. neivai and Lu. longipalpis protein extracts (data not shown). Immunoblotting with rabbit serum following immunisation against Max and Max peptide confirmed the immunisation specificity observed in the counterimmunoelectrophoresis. Subsequently, Max-immunised rabbit serum incubated with $N y$. neivai protein extract confirmed a protein fraction with a molecular weight similar to that of Max (Fig. 1).

PCR-RFLP and DNA sequencing indicated Max expression in Ny. neivai - PCR-RFLP and DNA sequencing revealed a 106-bp amplicon from $N y$. neivai extracts resembling the amplicon observed from $\mathrm{Lu}$. longipalpis extracts. Enzymatic restriction with $H h a \mathrm{I}$ and RsaI showed a similar restriction pattern in both samples (Fig. 2). DNA sequencing of a $248 \mathrm{bp}$-amplified fragment showed $66.5 \%$ Max gene homology (92\% identity and $100 \%$ similarity with the Max gene). This DNA sequence was deposited in GenBank (accession no. gi|148565454|gb|EF601123) (Fig. 3).

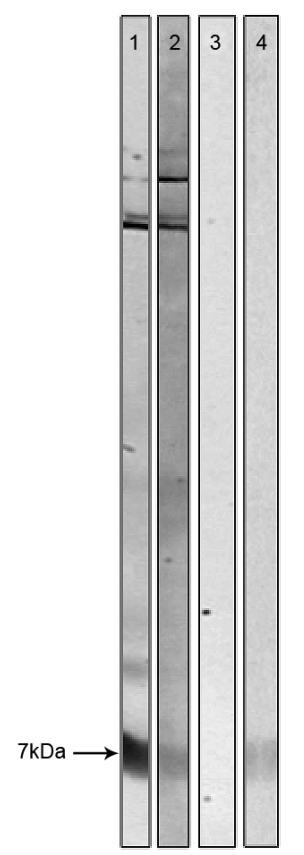

Fig. 1: immunoblotting with the protein extracts from Lutzomyia longipalpis (strip 1 and 3) and Nyssomyia neivai (strip 2) and from Maxadilan (Max) recombinant protein (strip 4). Strips 1 and 2 were incubated with anti-Max rabbit serum diluted 1:20; strip 3 was incubated with rabbit serum before immunisation diluted 1:20; strip 4 was incubated with anti-Max rabbit serum diluted 1:20. Anti-Max serum recognised a 7-kDa peptide (arrow).
Anti-Max values and ATL disease - Forty-one patients with ATL participated in the study (31 and 10 patients with the cutaneous and mucocutaneous clinical forms, respectively). The patients' median age was 45 years (minimum of three-years-old and maximum of 65 -years-old); $80.5 \%$ of the patients were male. The median duration of the disease in the patients with ATL was six months (minimum of one month and maximum of 300 months). The time for disease evolution was greater in patients with the mucocutaneous form than in patients with the cutaneous form of ATL (median of 66.0 months and 4.0 months, respectively; $\mathrm{p}<0.001$ ) (Table).

Anti-Max antibodies levels (presented as index values) were higher in the ATL patients than in the controls $(\mathrm{p}=0.0043)$ (Fig. 4). Based on a cutoff value of $1.0606,10 / 41(24.4 \%)$ of the patients with ATL and 2/63 (3.2\%) of the controls presented anti-Max levels above the cutoff $(p=0.0014)$. Anti-Max levels were not associated with the clinical form of ATL ( $p=0.7044)$, LST response $(p=0.8440)$, absence or presence of amastigotes in the histopathologic exam ( $\mathrm{p}=0.4697)$, IIF levels $(\mathrm{p}=$ $0.5893)$, or duration of the disease (0-4, 4-8, > 8 months) in the cutaneous form $(\mathrm{p}=0.2969)$.

\section{DISCUSSION}

Over the last few decades, the number of ATL cases has been increasing worldwide. In the Americas, the number of ATL cases has grown markedly, and Brazil has contributed the majority of the cases (Alvar et al. 2012). The state of São Paulo is not an exception: the

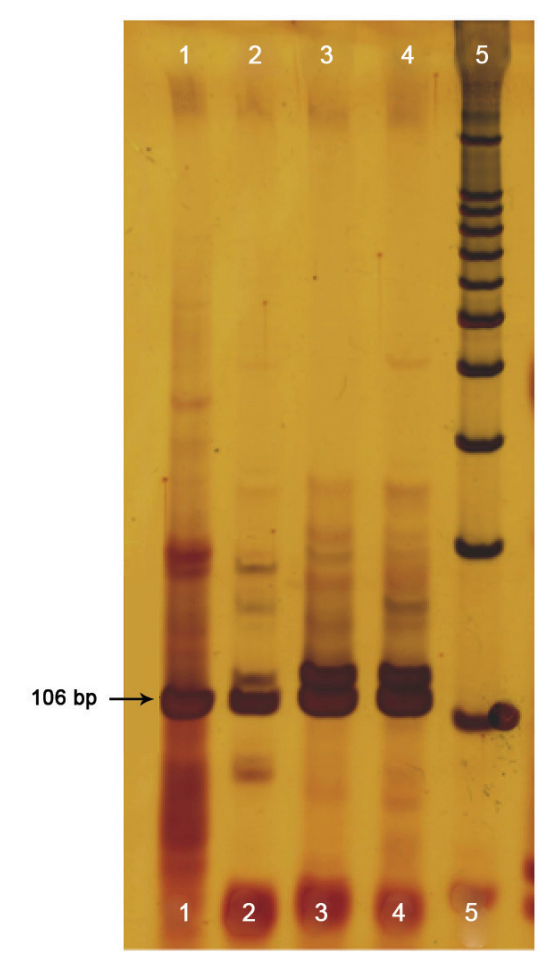

Fig. 2: a 10\% acrylamide gel showing 106-bp amplicons (arrow) using specific primers for Max. (1) DNA from Nyssomyia neivai; (2) cDNA from Ny. neivai; (3) DNA from Lutzomyia longipalpis; (4) cDNA from Lu. longipalpis; (5) molecular weight marker $=100 \mathrm{bp}$. 


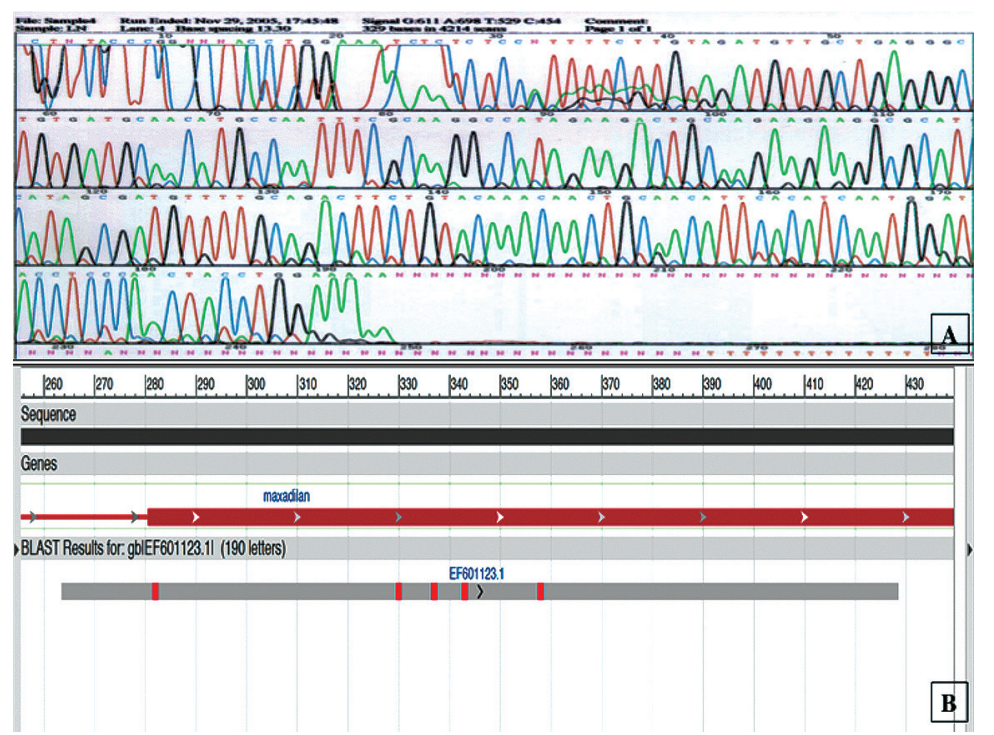

Fig. 3: the cDNA Maxadilan sequence is expressed in Nyssomyia neivai and was aligned with Maxadilan of Lutzomyia longipalpis. (A) cDNA sequencing confirmed a Maxadilan-simile fragment in Ny. neivai (gi|148565454|gb|EF601123); (B) alignment of a Maxadilan sequence from $L u$. longipalpis (gi|159451|gb|M7790.1|LUTMAX) and other Lu. longipalpis. Available from: http://www.ncbi.nlm.nih.gov/, accessed June 30, 2016.

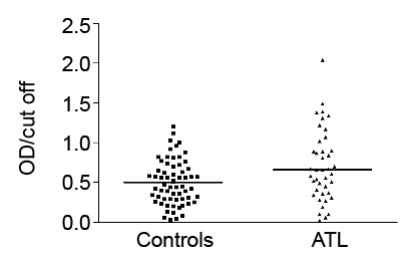

Fig. 4: antibodies against Maxadilan (presented as index values) identified by enzyme-linked immunosorbent assay in American tegumentary leishmaniasis (ATL) cases and the control group. Control group versus patient with ATL $(\mathrm{p}=0.0043)$. Index values were calculated from the OD (optical density, $492 \mathrm{~nm}$ ) value of each sample divided by the cutoff OD value. Cutoff: median OD values in the control group plus two standard deviations.

number of autochthonous ATL cases has increased, and the areas where cases are reported have expanded (SES-SP 2008). Sandflies that were formerly restricted to rural areas are now widely distributed across this state (Andrade Filho et al. 2007, Casanova et al. 2015).

$L u$. longipalpis has not been identified in the northeastern region of the state of São Paulo, and to our knowledge, autochthonous cases of VL have not been reported in this region (Casanova et al. 2015). In the same way, $N y$. intermedia, which is a vector of ATL in the state of São Paulo (Andrade Filho et al. 2007) with a Max homologue detected in its salivary gland transcriptome (de Moura et al. 2013), has not been identified in this region (Andrade Filho et al. 2007). Therefore, we decided to investigate whether $N y$. neivai, a sandfly vector of the pathogen responsible for ATL in the region, also harboured Max. Our results have shown that the Max gene is expressed in Ny. neivai (GenBank EF601123.1) and that this fragment shares $66.5 \%$ identity with Max from $L u$. longipalpis.

Regarding the $N y$. intermedia transcriptome, its Max homologue is very divergent ( $34 \%$ identity) and the pro- tein is present in low amounts compared to Max in Lu. longipalpis. As for Lu. ayacuchensis, another vector of cutaneous leishmaniasis in the New World, its transcriptome does not show Max gene expression, but large amounts of other vasodilator molecule genes such as adenosine and AMP are expressed (Kato et al. 2013).

Although blotting confirmed Max-simile peptide expression in the protein extracts of $N y$. neivai, the amount of this salivary protein deserves further investigation. Even though the cephalic segment, including the salivary glands, extracted from sandflies may have contained several contaminants for the blotting reaction, specific rabbit antibodies against Max recognised a 7-kDa peptide.

Mechanisms that enhance Leishmania infection in sandfly saliva are associated with its immunomodulatory properties (Titus \& Ribeiro 1988, Kamhawi 2000, Andrade et al. 2007). In experimental models, saliva from $L u$. longipalpis exacerbates infection caused by Leishmania (V.) braziliensis and Leishmania (L.) amazonensis when the saliva is inoculated together with the parasite (Samuelson et al. 1991, Laurenti et al. 2009). In contrast, saliva of wild-caught Bichromomyia flaviscutellata (Mangabeira, 1942) (= Lu. flaviscutellata) and Psychodopygus complexus (Mangabeira, 1941) (= Lu. complexa), vectors of Leishmania (L.) amazonensis and Leishmania $(V$.) braziliensis in the Brazilian Amazonian Region, respectively, exerts an inhibitory effect on parasite infection, resulting in small lesions and low levels of skin parasitism (Francesquini et al. 2014).

In mouse models, Max alone can exacerbate Leishmania infection to the same degree as whole salivary glands (Brodie et al. 2007), supporting the idea that it can be applied as a vaccine. In fact, mice vaccinated with Max show marked protection against Leishmania infection, producing not only anti-Max antibodies but also producing $\mathrm{CD} 4+\mathrm{T}$ cells against Max, generating 
IFN- $\gamma$, and inducing NO production (Morris et al. 2001). Immunisation against Max also inhibits blood meal acquisition by sandflies, so immunisation may help block reproduction in the vector (Milleron et al. 2004). Nonetheless, there is Max polymorphism; its amino acid substitution rate is approximately $23 \%$, and some amino acid sequences are not conserved (Warburg et al. 1994, Lanzaro et al. 1999). We may expect to find polymorphisms in Max-simile expressed in Ny. neivai.

Patients with ATL previously exposed to Max did not show protection against infection. Anti-Max antibody values were high in patients with the cutaneous and mucocutaneous forms of ATL, with either a positive or negative LST result, either the presence or absence of amastigotes in histopathologic samples, and either positive or negative IIF serology, suggesting that antibodies against Max do not interfere with specific immune responses to ATL. Patients with the aforementioned characteristics have responded well to treatment. In addition, we speculate that exposure to $N y$. neivai saliva components does not protect a person against infection or prevent the mucocutaneous form of ATL.

While the controls also presented anti-Max antibodies, their values were lower than those in ATL patients. Since the controls live in the same endemic region, we speculate that (i) they were bitten less frequently by sandflies than can be explained by epidemiological and environmental variables such as rural or urban occupation; (ii) they presented strong cellular immune responses ad weak humoral response against Max, resulting in against ATL; or (iii) they are genetically protected against ATL. It would be interesting to have data on the LST response in these individuals. A prospective study with blind evaluators could solve the limitations of our study.

Our data may encourage monitoring of human exposure to Max and to $N y$. neivai saliva components in ATL endemic regions. Some authors have also shown that vector density and the presence of antibodies against vector saliva are correlated (Clements et al. 2010). Antibodies against Max and antibodies against $N y$. neivai saliva components may be alternative serological markers to monitor ATL epidemiology in endemic regions. High titres of antibodies against Max in patients with ATL indicate previous exposure to vector bites, and, in our region, they represent previous exposure to the Max-simile peptide of $N y$. neivai.

Studies on the genetic and protein expression of Max-simile in Ny. neivai contribute to the development of new diagnostic approaches, a better understanding of ATL, knowledge of vectors in this endemic region. The examination of anti-Max antibodies in patients with ATL and controls confirms previous exposure to $N y$. neivai sandfly bites and suggests natural, chronic exposure to vectors. Therefore, antibodies against Max did not protect the host against ATL and could even enhance disease in our region. Further studies are essential to assess polymorphisms and the abundance of Max in Ny. neivai salivary glands. A description of the sialotranscriptome would also be of value.

\section{ACKNOWLEDGEMENTS}

To José Fernando Figueiredo, MD, PhD (in memorium), who contributed to all the phases of this study, and the staff working in the outpatient clinic at the University Hospital, Ribeirão Preto Medical School, University of São Paulo, Brazil.

\section{AUTHORS' CONTRIBUTION}

JA contributed with data collection, laboratorial experiments, data analysis, literature search and writing; $\mathrm{CC}$ contributed with data collection and analysis; SV contributed with data analysis, literature search, and writing; $\mathrm{MN}$ contributed with data collection, laboratorial experiments and data analysis; SR contributed with data collection, laboratorial experiments and data analysis; EAL contributed with data analysis, data interpretation and writing; and AMR contributed with study design, data collection, data analysis, data interpretation, literature search and writing.

\section{REFERENCES}

Alvar J, Vélez ID, Bern C, Herrero M, Desjeux P, Cano J, et al. Leishmaniasis worldwide and global estimates of its incidence. PLoS ONE. 2012; 7(5): e35671.

Andrade BB, de Oliveira CI, Brodskyn CI, Barral A, Barral-Netto M. Role of sand fly saliva in human and experimental leishmaniasis: current insights. Scand J Immunol. 2007; 66(2-3): 122-7.

Andrade Filho JD, Galati EAB, Falcão AL. Nyssomyia intermedia (Lutz $\&$ Neiva, 1912) and Nyssomyia neivai (Pinto, 1926) (Diptera: Psychodidae: Phlebotominae) geographical distribution and epidemiological importance. Mem Inst Oswaldo Cruz. 2007; 102(4): 481-7.

Brodie TM, Smith MC, Morris RV, Titus RG. Immunomodulatory effects of the Lutzomyia longipalpis salivary gland protein maxadilan on mouse macrophages. Infect Immun. 2007; 75(5): 2359-65.

Casanova C, Colla-Jacques FE, Hamilton JG, Brazil RP, Shaw JJ. Distribution of Lutzomyia longipalpis chemotype populations in São Paulo state, Brazil. PLoS Negl Trop Dis. 2015; 9(3): e0003620.

Champagne DE. The role of salivary vasodilators in bloodfeeding and parasite transmission. Parasitol Today. 1994; 10(11): 430-3.

Clements MF, Gidwani K, Kumar R, Hostomska J, Dinesh DS, Kumar V, et al. Measurement of recent exposure to Phlebotomus argentipes, the vector of Indian visceral Leishmaniasis, by using human antibody responses to sand fly saliva. Am J Trop Med Hyg. 2010; 82(5): 801-7.

Cruz CFR, Cruz MFR, Galati EAB. Sandflies (Diptera: Psychodidae) in rural and urban environments in an endemic area of cutaneous leishmaniasis in southern Brazil. Mem Inst Oswaldo Cruz. 2013; 108(3): 303-11.

de Moura TR, Oliveira F, Carneiro MW, Miranda JC, Clarêncio J, Barral-Netto M, et al. Functional transcriptomics of wild-caught Lutzomyia intermedia salivary glands: identification of a protective salivary protein against Leishmania braziliensis infection. PLoS Negl Trop Dis. 2013; 7(5): e2242.

Francesquini FC, Silveira FT, Passero LF, Tomokane TY, Carvalho AK, Corbett CE, et al. Salivary gland homogenates from wildcaught sand flies Lutzomyia flaviscutellata and Lutzomyia (Psychodopygus) complexus showed inhibitory effects on Leishmania (Leishmania) amazonensis and Leishmania (Viannia) braziliensis infection in BALB/c mice. Int J Exp Pathol. 2014; 95(6): 418-26.

Galati EAB. Morfologia e taxonomia: classificação de Phlebotominae. In: Rangel ER, Lainson R. Flebotomíneos do Brasil. Rio de Janeiro: Fiocruz; 2003. 368 pp.

Kamhawi S. The biological and immunomodulatory properties of 
sand fly saliva and its role in the establishment of Leishmania infections. Microbes Infect. 2000; 2(14): 1765-73.

Kato H, Jochim RC, Gomez EA, Uezato H, Mimori T, Korenaga M, et al. Analysis of salivary gland transcripts of the sand fly Lutzomyia ayacuchensis, a vector of Andean-type cutaneous leishmaniasis. Infect Genet Evol. 2013; 13: 56-66.

Lainson R, Rangel EF. Lutzomyia longipalpis and the eco-epidemiology of American visceral leishmaniasis, with particular reference to Brazil - A Review. Mem Inst Oswaldo Cruz. 2005; 100(8): 811-27.

Lanzaro GC, Lopes AH, Ribeiro JM, Shoemaker CB, Warburg A, Soares M, et al. Variation in the salivary peptide, maxadilan, from species in the Lutzomyia longipalpis complex. Insect Mol Biol. 1999; 8(2): 267-75.

Laurenti MD, Silveira VM, Secundino NF, Corbett CE, Pimenta PP. Saliva of laboratory-reared Lutzomyia longipalpis exacerbates Leishmania (Leishmania) amazonensis infection more potently than saliva of wild-caught Lutzomyia longipalpis. Parasitol Int. 2009; 58(3): 220-6.

Lerner EA, Ribeiro JM, Nelson RJ, Lerner MR. Isolation of maxadilan, a potent vasodilatory peptide from the salivary glands of the sand fly Lutzomyia longipalpis. J Biol Chem. 1991; 266(17): 11234-6.

Lerner EA, Shoemaker CB. Maxadilan. Cloning and functional expression of the gene encoding this potent vasodilator peptide. $\mathrm{J}$ Biol Chem. 1992; 267(2): 1062-6.

Marcondes CB. A proposal of generic and subgeneric abbreviations for phlebotomine sandflies (Diptera: Psychodidae: Phlebotominae) of the world. Entomol News. 2007; 118(4): 351-6.

Milleron RS, Ribeiro JM, Elnaime D, Soong L, Lanzaro GC. Negative effect of antibodies against maxadilan on the fitness of the sand fly vector of American visceral leishmaniasis. Am J Trop Med Hyg. 2004; 70(3): 278-85.

Morris RV, Shoemaker CB, David JR, Lanzaro GC, Titus RG. Sandfly maxadilan exacerbates infection with Leishmania major and vaccinating against it protects against $L$. major infection. J Immunol. 2001; 167(9): 5226-30.

Neitzke-Abreu HC, Reinhold-Castro KR, Venazzi MS, Scodro RB, Dias AC, Silveira TG, et al. Detection of Leishmania (Viannia) in Nyssomyia neivai and Nyssomyia whitmani by multiplex polymerase chain reaction, in southern Brazil. Rev Inst Med Trop São Paulo. 2014; 56(5): 391-5.

Roberts MT. Current understandings on the immunology of leishmaniasis and recent developments in prevention and treatment. Br Med Bull. 2005; 75-76(1): 115-30.

Samuelson J, Lerner E, Tesh R, Titus R. A mouse model of Leishmania braziliensis braziliensis infection produced by coinjection with sand fly saliva. J Exp Med. 1991; 173(1): 49-54.

SES-SP - Secretaria de Estado da Saúde de São Paulo. Leishmaniose tegumentar americana, situação atual, 2008 [Internet]; cited 2016, June 30. Available from: http://www.saude.sp.gov.br/.

Titus RG, Bishop JV, Mejia JS. The immunomodulatory factors of arthropod saliva and the potential for these factors to serve as vaccine targets to prevent pathogen transmission. Parasite Immunol. 2006; 28(4): 131-41.

Titus RG, Ribeiro JM. Salivary gland lysates from the sand fly Lutzomyia longipalpis enhance Leishmania infectivity. Science. 1988; 239(4845): 1306-8.

Vernal S, de Paula NA, Gomes CM, Roselino AM. Disseminated Leishmaniasis by Leishmania viannia subgenus: a series of 18 cases in southeastern Brazil. Open Forum Infect Dis. 2016; 3(1): ofv184.

Warburg A, Saraiva E, Lanzaro GC, Titus RG, Neva F. Saliva of Lutzomyia longipalpis sibling species differs in its composition and capacity to enhance leishmaniasis. Philos Trans R Soc Lond B Biol Sci. 1994; 345(1312): 223-30.

Young DG, Duncan MA. Guide to he identification and geographic distribution of Lutzomyia sand flies in Mexico, the West Indies, Central and South America (Diptera: Psychodidae). Mem Amer Ent Inst. 1994; 54: 887 pp. 